Article

\title{
The Geopolitical Energy Security Evaluation Method and a China Case Application Based on Politics of Scale
}

\section{Zhiding $\mathrm{Hu}^{1}$ and Yuejing $\mathrm{Ge}^{2, *}$}

1 Institute of Geographic Sciences and Natural Research, Chinese Academy of Science, Beijing 100101, China; E-Mail: huzhiding2007@126.com

2 School of Geography, Beijing Normal University, Beijing 100875, China

* Author to whom correspondence should be addressed; E-Mail: geyj@bnu.edu.cn; Tel.: +86-139-1062-6308; Fax: +86-10-5880-7657.

Received: 30 April 2014; in revised form: 30 July 2014 / Accepted: 11 August 2014 / Published: 27 August 2014

\begin{abstract}
Combining the theories of politics of scale from political geography, security theory from international relations, and energy security theory, and putting the scale conversion of energy contention, geographical relationship and geo-structure in geo-setting, and the three properties of safety in consideration, this paper rebuilds a geo-energy security evaluation model and uses the model to quantitatively evaluate China's geo-oil energy security in the Russian Pacific oil pipeline construction from 1995 to 2010. Five results could be drawn as follows: (1) from the aspect of time, an up-surging Geo-oil Safety Index of China in the Russian Pacific oil pipeline construction indicated an increasingly disadvantage of China in the geo-oil contention by politics of scale. If the United States and South Korea are involved, the competition would be further intensified; (2) from the aspect of geopolitical relationship, a general decrease occurred in the Sino-Japan Energy Competition Index, but a specific increase appeared in the competition of energy imports from Russia, by China and Japan individually; (3) from the aspect of regional strategy of energy export, an obvious downward tendency in Energy Export Strategy Index showed that Russia has changed its export destination off of Europe; (4) from the aspect of geo-security, a relatively steady proportion of China's oil consumption, and a friendly comprehensive strategic partnership of cooperation between China and Russia, reduced the worries of China's geo-oil energy security to some extent; (5) from the aspect of geopolitical structure, the increasing comprehensive national power in China, driven by rapid economic growth, will intensify the geo-oil competition in Northeast Asia.
\end{abstract}


Keywords: political geography; politics of scale; energy security; Russian pacific oil pipeline

\section{Introduction}

Energy is the most basic power source of human social development [1], the basic limiting condition of the development of economy and the progress of civilization, and an important foundation of national economy, national security, and the realization of sustainable development [2]. In particular, the emergence of two oil crises in the 1970s highlight the energy security issue, which has become a focus for all nations [3]. Recently, with the continuing high-speed development of China's economy, China has become the largest developing energy consumer and production country in the world, and the energy issue has become a top priority among the many problems in China in the $21 \mathrm{st}$ century, the energy security issue being the core issue [4]. Domestic and foreign scholars have studied the energy security issue extensively from different points of view. Foreign scholars, such as Larry Hughes (2009), Anil Markandya (2010), Mamdouh (2003), Helen Cabalu (2010), and Kruyt (2009), studied energy security with regard to its connotations (including four aspects: cognitive problems, reducing energy consumption, seeking secure alternate energy species, and prohibiting newly increased energy demand), policy (such as energy tax policy), measures (developing mixed fuel, diversifying sources of imports, increasing energy efficiency, and making laws to supervise and manage import dependence), safety evaluation index, and so on [5-9]; a group of domestic scholars represented by Liu Yi (1996, 1999), Zhang Lei (2012), Yihuan Lang (2004), Xianjie He (2010), and others, conducted research on China's energy security in terms of the aspects of concept, theory, the evaluation method, the supply and demand assurance method, countermeasures, and so on, thus, providing a basis for decision-making related to national energy security and macro-control [10-14].

However, early in the 1930s, Daniel Yergin, chairman of the Cambridge Energy Research Associates and a celebrity of the international oil industry, described the European oil market, at that time, as follows: "oil consists of 10\% economy and 90\% politics". Today, Daniel Yergin describes the oil market in the following way: "any other raw materials cannot match the close relationship that exists in oil and geopolitics, which can be confirmed in the Middle East, Russia, China, Latin America or even any region in the world" [15]. This is to say that research on oil, or oil energy security, cannot be separated from politics, especially geopolitics. As to this point, China's scholars Yihuan Lang, and Limao Wang et al. conducted related research focused on the levels of energy in a geopolitical strategy [16], energy geopolitical patterns [17], formation mechanisms [18], and related policies. However, until now, few people have truly applied the geopolitics theory to energy security evaluation.

To truly combine geopolitics theory with the energy security evaluation method, it is necessary to complete a comprehensive analysis of the manner in which geopolitics affects energy security. To achieve this goal, during the early stage of our research, we chose Russia's Pacific oil pipeline construction as an example. From the perspective of geopolitics, we discuss the dispute of Russia's Pacific pipeline from beginning to end with regard to the interdependence of spatial relationships, interference factors, distance, mode of transportation, and so on [19]. It paves the way for further quantitative evaluation of energy security from the perspective of geopolitics. 
Evaluating energy security from the aspects of energy supply stability, energy demand, energy use security, energy consumption structure, and so on, at the national or regional level [20], presents only one evaluation idea. This method cannot truly begin with the source of energy security, namely the transportation route design for energy supply or overseas energy strategy, to evaluate the energy security situation relating to original energy transportation design or energy strategy design. This situation cannot be summarized in terms of the field of energy production and energy transportation, or even incorporated into the field of energy use security. Geo-energy security involves a portion of this field, but additionally, it has its own security core. Beginning in 1994, and involving Japan in 2002, the Sino-Russian Pacific oil pipeline construction initially involved the Angarsk Angarsk-Nakhodka line, and is eventually set to involve the Taine line, imposing a great challenge to China's energy security strategy, possibly preventing a similar setback in the energy dispute. This thesis has important theoretical and practical significance for the evaluation of the energy security situation from the source. The subject of the thesis consists of three parts: the first part is the theoretical foundation of the geo-energy security evaluation method, primarily involving politics of scale theory in political geography, security theory in international relations, and energy security theory; the second part is the construction of the geo-energy security evaluation method; the third part is the application of the model, for which Russia's Pacific oil pipeline construction is chosen as an example, and empirically analyzes the geo-oil energy security situation of China in this geographical scope between 1995 and 2010.

\section{Theoretical Foundation}

\subsection{Politics of Scale Theory}

Space [21], place, landscape, network, and scale, constitute the basic conceptual system of human geography [22], and scale has gained considerable progress in political geography. It can even be asserted that the attention that human geography devotes to scale originated with Taylor (1982) and Smith's (1990) groundbreaking research on scale in political geography [23,24]. The 1997, Volume 16 Number 2 issue of Political Geography discusses the scale problem in the form of a monograph. Political geography research on scale focuses on the words "politics of scale", which initially appeared in the book "Uneven development: nature, capital and the production of space", published by Smith in 1990. Soon afterwards, the concept of scale was developed in Cox's book "Space of Globalization", in which the author studied how the indigenous qualities of a scale as a political and economic organization depended on each other in the process of globalization (1998), which is still a rather important research idea today [25]. Herod and Wright's book (2002), "Geographies of power: placing scale", focuses on the three aspects of politics of scale, namely, theorized scale, scale rhetoric, and scale practice [26]. In addition, Brenner (1998), Marston (2002), and Flint and Taylor (2007) applied politics of scale to regional restructuring of globalization, scale process of consumption, and social reproduction processes and the election respectively [27-29]. China's scholar, Yungang Liu (2011), first introduced the words "politics of scale", as well as discussed its theoretical progress, and applied it to the analysis of the Sanlu milk powder incident [30]. 
The core of politics of scale theory is that according to their own benefits, different behavior subjects perform necessary scale conversion by using their own power or introducing third-party behavior subjects to expand their own power and by controlling and manipulating scale, thus selecting a scale that is beneficial to themselves. Generally speaking, the number of behavior subjects involved in politics of scale theory should not be less than two. Various behavior subjects limit or expand the scale of an event by using their own power or by receiving assistance from an external power with the reason to obtain the most advantageous scale and satisfy their own political and economic demands. This struggle constitutes the scale contest in the politics of scale [31]. The scale manifests itself in two ways, direct struggle and the mobilization of external support [30], and, when specified in event analysis, it manifests in the application of mobility tools, means of expression and regulatory means, whereas in space, it manifests in upscaling and downscaling.

\subsection{Security Theory}

Security is one of the most prominent problems that humans face, whether it is personal security, national security, or international security, and few deny the existence of this problem [32]. At the same time, security is the core element of international relationship [33]. However, the analysis of security has always been very immature in international relationship research, and there are at least five explanations for it. Thus, the security concept is "essentially a controversial concept" [34]. As famous security research expert Barry Buzan noted, "security" was a very incomprehensively developed and highly controversial concept [35]. The notion that "a concept is rather controversial essentially" indicates that it not only has a "coexistence of use" problem, but also that it is broad, free to answer, and fuzzy in implication [36]. This is just as Helga Haftendorn said (1991): "there is no common understanding of what security is, how it is defined and what is its most relevant research problem" [37]. The final result is that the definition of the security concept can be divided into the aspects of axiology, state theory, ability theory, sensualism, and practice theory.

Based on many scholars' understanding of security concepts, we can generalize the three properties of security: the subjective property, the objective property, and intersubjectivity. The objective aspect of security is the security status of the outside world, whereas the subjective aspect of security is the mentality of people's comprehension of security. In general, the subjective and objective aspects of security are correlated. The behavior subject cannot be irresponsive subjectively when endangered objectively. On the contrary, even if there is no actual dangerous behavior toward the behavior subject objectively, if the behavior subject inwardly feels the existence of other threats, security is nonexistent. This notion was mentioned by Arnold Wolfers when studying security in 1962. He noted that security research could be both close to objectivity (the existence of a real threat) and close to subjectivity (the existence of a realized threat) [38]. The intersubjectivity of security is the research of security from the perspective of practice theory. Barry Buzan, Orly Aviv, and Di Wilder (2003) clearly note that securitization must be perceived as an intersubjective process, like politicization [39]. A very well-known example of this process is North Korea's development of nuclear weapons. For countries such as America, South Korea, and Japan, North Korea's development of nuclear weapons is an obvious and rather challenging behavior that threatens national security. However, for many countries similar to China, although the behavior of North Korea's development of nuclear weapons objectively constitutes 
a threat, such a threat is not considered or perceived as a behavior threatening their national security. A key to recognizing the intersubjectivity of security lies in the difference in behavior subjects and the degree to which security cognition is shared among behavior subjects. Therefore, security ultimately maintains a characteristic that is neither subject nor object; rather, security is intersubjective. To this end, the evaluation of security must consider the three properties of security.

\subsection{Energy Security Theory}

The proposal of the concept of energy security stems from the oil crisis in the 1970s. After the establishment of the international energy agency in 1974, the concept of national energy security was formally proposed, the core of this concept being the stabilization of crude oil supply and price security. The signing of the Kyoto Protocol in 1997 marked the start of countries considering the endowment of energy security with environmental protection and sustainable development connotations. Thus, energy security is defined as a country or religion able to obtain a stable, adequate, economic and clear energy supply to meet demand, ensure stable economic and social operation, and guarantee the ability and status of sustainable and coordinated development [40].

Therefore, currently, the evaluation of energy security is developed in terms of three aspects. One aspect is the stability of energy supply, meaning the stability of satisfying the energy security guarantee of normal requirements used for national survival and development, which involves the ration of energy production and consumption, the diverse index of production, the risk index of transportation, market liquidity, foreign dependence, and so on. Another aspect is the security of energy use, which means that the consumption and use of energy should not threaten human survival and the development environment. This aspect involves energy consumption per GDP, carbon consumption, renewable energy usage, the structure of energy use, the economy, and so on. The third aspect involves the stability of energy demand, which is the premise of energy supply guarantee security, as well as the basic starting point for energy security research, and involves economic development, industrial energy use intensity, industrial structure, population growth, and per capita consumption.

\section{The Construction of the Geo-Energy Security Evaluation Method}

\subsection{Ideas of Geo-Energy Security Evaluation}

There is a link between geo-energy security and energy security, but there are more differences between them. The link indicates that the acquisition of geo-energy security can reduce the instability of energy security to a certain extent. As the security object or behavior subject of both sides is state. However, the differences are reflected in the "geo-" and "behavior". The word "geo-" is used as prefix to modify energy security and illustrates the relation between energy security and geo-setting, which also indicates that the geo-energy security evaluation is not energy security evaluation, but, rather, the evaluation of the impact of geo-setting on energy security. Security theory clearly indicates that security is the security among behavior subjects and involves more than one behavior subject. Therefore, the object of energy security evaluation is concentrated in one country or region, whereas geo-energy security involves at least two behavior subjects and concerns the behavior among behavior subjects and the security status of joint decision with regard to the characteristics of behavior subjects. 
According to the three properties of security indicated by security theory, particularly subjectivity, and intersubjectivity, the first step in quantitatively evaluating geo-energy security must determine the involved object or behavior subject of security, which is also the core link in politics of scale; that is, the relative strength contrast between behavior subjects determines the scale space range in contention. At the same time, it determines the source of evaluating threat and fragility. Early energy security evaluation was a type of security evaluation that was close to objectivity while lacking subjective and intersubjective properties of security. Additionally, this type of evaluation even lacked game analysis among behavior subjects, whereas game theory is one of the most important methods of studying energy security in economics [41]. As early as 1978, Willrich divided energy security into energy security of the exporting and importing country, which is to clear the subject of energy security. The second step is to determine the direction of geo-energy security evaluation [42]. According to the five dimensions of the security concept, insecurity is a comprehensive reflection of threat and vulnerability. Threat conveys the objective property of security and is a direct expression of state theory, whereas fragility is the subjective property of security and a direct expression of ability theory and feeling theory. The third step defines the range of geo-energy security evaluation, unearths influencing factors belonging to geo-energy security range, excludes indexes belonging only to energy security evaluation range, and truly reflects the influence of geo-setting on energy security. By introducing the geographical relationship of geo-setting, the intersubjectivity of security is fully reflected. So the evaluation of ideas of Geopolitical energy security is as shown in Figure 1.

Figure 1. The evaluation of ideas of Geopolitical energy security.

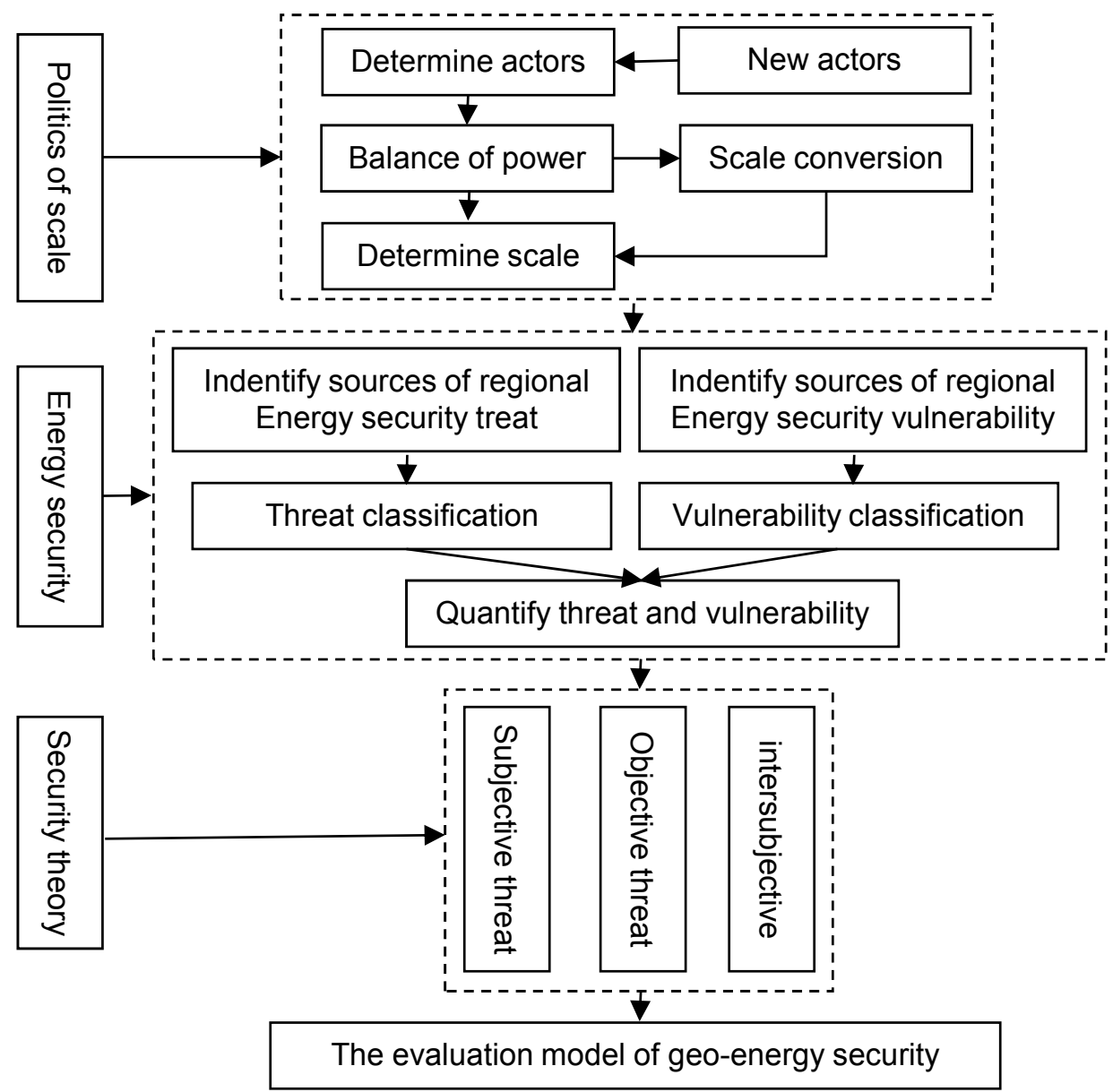




\subsection{Evaluation Model}

According to the ideas of geo-energy security evaluation, the core of geo-energy security evaluation is behavior subjectivity. The balance of power of behavior subjects determines the scale range of energy contention, clears the direction of quantified threat and fragility in security evaluation, and even finds the basic point of the implementation of the three properties of security. For this purpose, we first introduce Klein's comprehensive evaluation equation of national strength as the basis of the geo-energy security evaluation model. He proposed a model of quantitatively evaluating and analyzing national power, the expression of which is as follows [43]:

$$
\mathrm{P}_{\mathrm{P}}=(\mathrm{C}+\mathrm{E}+\mathrm{M}) \times(\mathrm{S}+\mathrm{W})
$$

In this expression, $P_{p}$ denotes the confirmed national power, $C$ denotes the basic entity, including population and territory, $E$ denotes economic ability, $M$ denotes military ability, equivalent to strategic force plus conventional military force, $S$ denotes strategic intent, and $W$ denotes the will to implement a national strategy.

The structure of this model can be divided into two parts: the first part consists of a nation's basic entities, economic ability and military ability, whereas the second part consists of strategic intent and will with regard to national strategy. Additionally, the comprehensive national strength is designed as the product of the two parts. The construction mode of this model basically agrees with the abovementioned ideas of evaluating geo-energy security, namely, the inclusion of the behavior subject itself, as well as the behavior characteristics and subjective factors of the behavior subject. Therefore, we modify the model as follows:

$$
\text { GeoES } S_{i}=\left(B_{i}+C_{i}+D_{i}+E_{i}+F_{i}\right) \times\left(\alpha S_{j}+\beta W_{i j}\right)
$$

In the formula, GeoES $S_{i}$ (Geo-energy security) denotes the geo-energy security index of country $i$, $B_{i}$ denotes the growth rate of energy consumption of country $i, C_{i}$ denotes the structure index of energy consumption of country $i$ or the ratio of oil consumption to total energy consumption if evaluating geo-oil energy security, $D_{i}$ denotes the energy gap index of country $i, E_{i}$ denotes the diverse index of energy imports of country $i, F_{i}$ denotes the energy competition index between countries, $\alpha$ denotes the number of energy competitive countries, $S_{j}$ denotes the geo-energy strategy index of energy-exporting country $j, \beta$ denotes the geo-structure situation of the region and is expressed as the proportion of the economic strength of country $i$ to the region, and $W_{i j}$ denotes the geographical relationship of country $i$ and country $j$, and is calculated using the event analysis method for the national relationship.

$$
C_{i}=\frac{m^{k}}{M}
$$

in which $m^{k}$ denotes the total consumption of $k$ types of energy and $M$ denotes total energy consumption.

$$
D_{i}=\frac{M-N}{M}
$$

in which $M$ denotes total energy consumption and $N$ denotes total energy production.

$$
E_{i}=\sum_{k=1}^{3} \frac{g_{k}}{G}
$$


In this expression, $g_{k}$ denotes the amount of imported energy of the first three regions of a country importing energy from elsewhere in the world and the import regions must be the same. $G$ denotes total energy import.

$$
S_{j}=\frac{\mathrm{H}}{\Phi}
$$

in which $H$ denotes the total energy output of country $j$ in other primary regions and $\Phi$ denotes the total energy output of country $j$.

According to the theoretical basis of geo-energy security evaluation and the specific evaluation model, it is clear that politics of scale are primarily reflected in three aspects in the model: (1) the conversion of politics of scale determines the countries or potential countries in the geo-energy security competition, and $\alpha$ in the model is a partial index reflecting politics of scale; (2) after determining competing countries using scale conversion, the national energy competition index $F_{i}$ is also an index reflecting politics of scale; (3) politics of scale is also reflected in the geographical relationship between the countries, namely $W_{i j}$ in the model. The conversion of scale can lead to changes in competing countries and the formation of different geographical relationships. Politics of scale conversion power sources include the growth rate of energy consumption of importing countries $\left(B_{i}\right)$, energy consumption structure $\left(C_{i}\right)$, energy gap index $\left(D_{i}\right)$, index of diversification $\left(E_{i}\right)$, geopolitical energy strategic of exporting country $\left(S_{j}\right)$, and geographic relationship between import-exporting countries $\left(W_{i j}\right)$.

The introduction of security theory primarily avoids the particular stresses on objective security during the early stages of energy security evaluation and ignoring the subjective property and intersubjective characteristics of security. National energy strategy index $S_{j}$ and geographical relationship $W_{i j}$ reflect the subjective property and intersubjectivity of security, respectively. Other indexes in the model reflect energy security theory.

\section{Model Application: Russia's Pacific Oil Pipeline Construction}

\subsection{Scale Conversion}

In 1994, Russia Yukos oil company made a proposal to China, involving the building of an oil pipeline from Angarsk to Daqing in China (namely, "Angarsk", see Figure 2), and planned to export 30 million tons of oil to China every year. China responded to the proposal, and the two governments signed (the Sino-Russia agreement on conducting a joint cooperation in the field of energy) in 1996. In September of 2001, the joint communiqué issued by the sixth regular meeting between the Chinese and Russian prime ministers, and the Sino-Russia Joint Statement signed by Chinese and Russian chief executives in December of 2002, both established the scale range of Russia's Pacific oil pipeline construction between China and Russia. Some research scholars note that the primary reasons for delaying the implementation of the Sino-Russia oil pipeline construction were that both sides lacked sufficient trust in the other side and that both sides lacked precise judgment regarding the future international energy situation at that time [44]. The deeper reason for the delay is the contrast between Chinese and Russian geo-energy power. The purpose of Russia's proposal to build Angarsk was to expand its energy export diversity. If the line was designed initially to expand to countries other than 
China, such as Japan and South Korea, it was bound to influence the enthusiasm of China's participation. The sources of China's oil imports indicated that $45.4 \%$ of China's oil imports originated from the Middle East in 1995, a figure that rose to 53.6\% in 2000, and that China's oil imports from Africa rose from $10.8 \%$ in 1995 to $23.9 \%$ in 2000 , whereas crude oil from Russia totaled only $2.1 \%$ in 2000 . Therefore, Russia could only design an oil transport line between China and Russia. However, this did not impact that Russia decided to wait for the emergence of a third country to realize an energy export diversification strategy. Until 2004, the percentages of Russian oil exports to America, Japan, and China were only $1.92,0.31$, and 3.35, respectively [45]; therefore, neither China nor Russia was eager to accelerate the construction of Russia's Pacific oil pipeline.

After 2002, China's oil import dependency increased significantly: it totaled $44.64 \%$ in 2003 , broke $50 \%$ in 2004 , and was at $52.86 \%$ in 2010 . China must further strengthen cooperation with Russia with regard to oil energy security to realize the diversification of oil energy imports. After 2003, Japan promised to import one million tons of oil from Russia every day and prepared to provide a five billion dollar loan to aid Russia in building an oil pipeline. By waiting for the emergence of a third party, Russia successfully realized the conversion of oil politics of scale. Thus, Russia could increase bargaining power by utilizing the China-Japan rivalry. In particular, soon afterwards, Japan successively proposed totals of 7.5 billion dollars and 9 billion dollars, plus 12 billion dollars of supporting investment, and China was forced to provide 25 billion dollars of loans in exchange for the official start of the oil pipeline construction. In the oil politics of scale contention, China turned its early advantage into a disadvantage due to Japan's participation.

Figure 2. The scale conversion of Russia's pacific oil Pipeline construction.

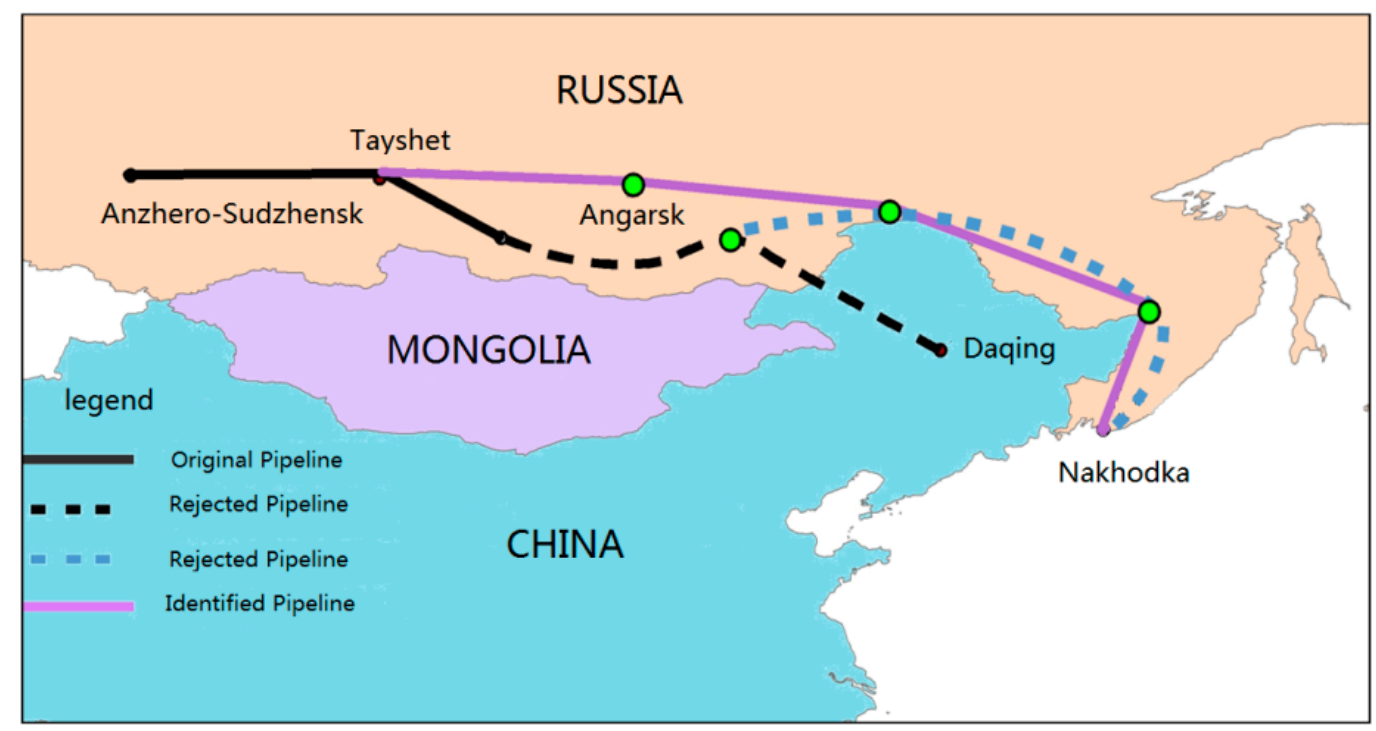

\subsection{Data and Their Explanation}

The above formulas are designed to evaluate geo-energy security, and they must be modified to calculate the geo-oil energy security index. The explanation for this modification is as follows: $B_{i}$ is modified as the sum of country $i$ 's oil energy consumption growth rate and total energy consumption growth rate; $C_{i}$ denotes the ratio of country $i$ 's oil consumption to total energy consumption; $D_{i}$ denotes the sum of country $i$ 's oil consumption gap and total energy consumption gap; $E_{i}$ denotes 
the oil energy import diversification index of country $i$; and $F_{i}$ denotes the index of oil energy competition between countries.

The calculation must include data on the following between 1995 and 2010, as shown in Table 1: China's annual total energy consumption, total energy production, total oil energy consumption, total energy imports, and energy imports from different regions; Russia's total energy exports and total energy exports to different regions; Sino-Russian annual important international events; and the economic aggregate of China, Russia, Japan, and South Korea.

Table 1. Geo-oil energy security evaluation data set.

\begin{tabular}{|c|c|c|c|c|c|c|c|c|c|c|}
\hline Year & $\boldsymbol{B}_{i}$ & $C_{i}$ & $D_{i}$ & $E_{i}$ & $F_{i}$ & $S_{j}$ & $W_{i j}$ & $\beta$ & $\alpha$ & GeoES $_{i}$ \\
\hline 1995 & 0.1155 & 0.175 & 0.0832 & 0.8733 & - & 0.6968 & 9.000 & 0.1094 & \multirow{8}{*}{2} & 2.965 \\
\hline 1996 & 0.0863 & 0.180 & 0.0127 & $0.8569 *$ & - & $0.7121 *$ & 7.841 & 0.1278 & & 2.756 \\
\hline 1997 & 0.1276 & 0.204 & 0.1900 & 0.8408 & - & 0.7278 & 7.144 & 0.1481 & & 3.424 \\
\hline 1998 & 0.0551 & 0.215 & 0.2353 & 0.8314 & - & 0.7358 & 6.626 & 0.1740 & & 3.508 \\
\hline 1999 & 0.1095 & 0.226 & 0.3061 & $0.8157 *$ & - & $0.7519 *$ & 6.107 & 0.1683 & & 3.689 \\
\hline 2000 & 0.0932 & 0.232 & 0.3530 & $0.8003 *$ & - & $0.7685 *$ & 5.550 & 0.1798 & & 3.747 \\
\hline 2001 & 0.0521 & 0.229 & 0.3274 & 0.7939 & - & 0.7875 & 5.749 & 0.1888 & & 3.731 \\
\hline 2002 & 0.1334 & 0.234 & 0.3855 & 0.7649 & - & 0.8119 & 5.550 & 0.2044 & & 4.186 \\
\hline 2003 & 0.2182 & 0.222 & 0.4425 & 0.7964 & 0.8964 & 0.8534 & 5.521 & 0.1880 & & 9.267 \\
\hline 2004 & 0.2818 & 0.223 & 0.5251 & 0.7737 & 0.8672 & 0.8306 & 5.673 & 0.1909 & & 9.547 \\
\hline 2005 & 0.1350 & 0.210 & 0.5258 & 0.7567 & 0.7861 & 0.8223 & 5.580 & 0.2533 & & 9.365 \\
\hline 2006 & 0.1485 & 0.204 & 0.5765 & 0.7325 & 0.7013 & 0.8152 & 5.431 & 0.2951 & & 9.565 \\
\hline 2007 & 0.1229 & 0.197 & 0.6115 & 0.6937 & 0.6930 & 0.8078 & 5.105 & 0.3122 & 3 & 9.312 \\
\hline 2008 & 0.0236 & 0.187 & 0.5930 & 0.7047 & 0.6915 & 0.7868 & 5.099 & 0.3414 & & 9.022 \\
\hline 2009 & 0.0622 & 0.18 & 0.6090 & 0.6806 & 0.6882 & 0.7779 & 5.779 & 0.4209 & & 10.58 \\
\hline 2010 & 0.0911 & 0.176 & 0.6148 & 0.6614 & 0.6653 & 0.7008 & 5.595 & 0.4238 & & 9.880 \\
\hline
\end{tabular}

Source: Author's computations. * obtained by the time series interpolation.

\subsection{Result Analysis}

(1) From the time point of view, China's geo-oil security index in the Russian Pacific oil pipeline construction rose continually, indicating that China was increasingly at a disadvantage in the oil energy politics of scale contention (Figure 3). The most influential factor of the disadvantage was Japan's intervention, which led directly to the conversion of the contest between China and Russia into a simultaneous contest between China and Japan and between China and Russia in the oil politics of scale contention. Second, the oil energy gap index of China continually increased $\left(D_{i}\right)$, equaling only 0.0832 in 1995, breaking 0.2 in 1998 and 0.5 in 2004, and reaching 0.6148 in 2010, thus, indicating an annual growth rate of almost $7 \%$. Third, the growth rate of oil and total energy consumption was on the high side $\left(B_{i}\right)$; particularly from 2002 to 2007, the growth rates all contained more than two digits. Fourth, the change in the geopolitical structure of Northeast Asia hindered China's oil energy import in a certain extent. Before 2002, the ratio of China's economic strength to that of China, Russia, Japan, and South Korea was less than 20\%, and its growth rate was always slow. After 2002, China's rise was rapid, and the economic strength ratio reached $42.38 \%$ in 2010 . Neither Russia, Japan, nor South Korea will sit back and watch China's rise and dominance. 
(2) From the geographical relationship point of view, the energy competition index of China and Japan tended to decrease $\left(F_{i}\right)$, but the competition between the two countries in terms of importing energy from Russia intensified. The energy competition index of China and Japan decreased from 0.8964 in 2003 to 0.6614 in 2010 . This decrease indicates that the two countries avoided the convergence of the oil energy import region in terms of the energy import diversification aspect. However, in some regions, particularly when viewed in terms of the two countries' oil energy imports from Russia, the competition tended to intensify further. In 2002, China imported 5.3 million tons of oil from Russia, and this grew to 48.6 million tons in 2011, indicating an annual growth rate of $27.9 \%$; although the amount of Japan's imports from Russia was not very large, its growth was quick: in 2002, it measured 0.7 million tons and, in 2011, it measured 14.5 million tons, indicating an average annual growth rate of $40.4 \%$.

(3) Russia's energy export strategy had long been biased toward Europe, but a steering trend emerged. For some time, the object of Russia's oil energy exports was the European region, accounting for almost $70 \%$ of domestic oil energy. From 2002 to 2007, these exports almost exceeded $80 \%$, which, on the one hand, influenced Russia's energy export security and, on the other hand, was not conducive to the realization of its geo-energy strategy. After 2007, Russia's oil energy exports to Europe began to decrease, falling to $70 \%$ in 2010. As Russia's medium- and long-term strategy of energy is implemented, the trend will continue, which will decrease the threat of China's energy import to a certain extent.

(4) The proportion of China's oil consumption and the friendly relationship between China and Russia relieve China's geo-oil energy security. China's energy consumption has been dominated by coal, whereas the oil consumption proportion is generally maintained at approximately $20 \%$. Although total oil consumption increases relatively quickly, it is low in relation to the overall energy consumption structure, which can relieve the pressure of oil energy import to a certain extent. In addition, China and Russia have maintained a friendly relationship since 1995, which plays an important role in China's geo-oil energy security.

(5) From the geo-structure point of view, the increase in the overall national strength driven by China's economic growth will intensify geo-oil competition in Northeast Asia. In 1995, China's economic aggregate accounted for only $10.94 \%$ of the economic aggregate of China, Russia, Japan and South Korea, whereas in 2010 , it increased to $42.38 \%$. The stable geo-structure of Northeast Asia formed by powers of considerable strength is changing because of China's rise. From the perspective of maintaining national security interests, Russia, Japan, and South Korea do not expects dominance by China. This element is bound to influence Russia's energy export and increase the energy competition intensity of countries, such as Japan and South Korea. China's geo-oil competition in this region will further intensify. 
Figure 3. The Geo-oil security index change.

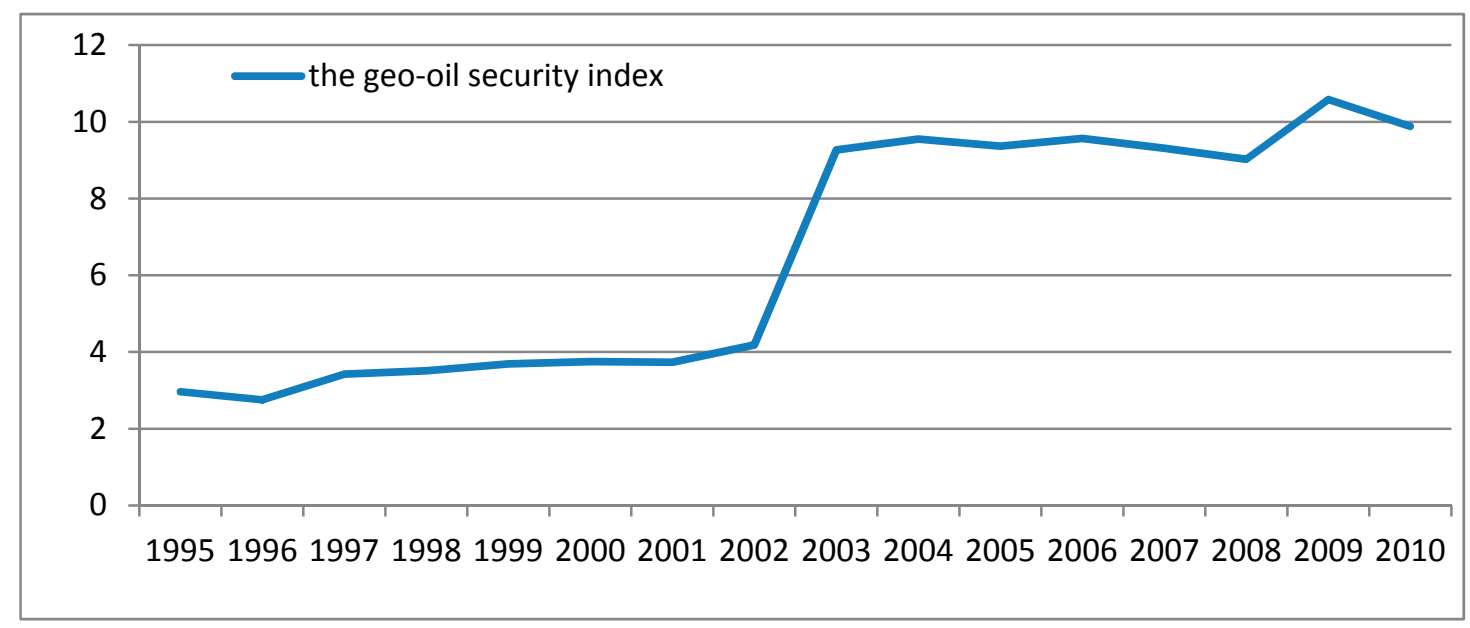

\section{Conclusions and Discussion}

By introducing the politics of scale theory, security theory, and energy security theory, this paper constructs the geo-energy security evaluation model. Additionally, with the assistance of the example of Russia's Pacific oil pipeline construction, the paper quantitatively evaluates China's geo-oil energy security situation in this region. The choice of the case has the very good representative. Due to its length of time, scale and the number of the behavior body are very appropriate.

The geo-energy security evaluation model constructed in this paper has several outstanding characteristics in comparison with early energy security evaluation models. First, it considers multiple properties of security, whereas early energy security evaluation models only consider the objective aspect of security and lack the evaluation of the subjective aspect and the intersubjectivity of security. Second, the geographical aspect is strong, and the relationship between oil and geo-politics is inseparable; ignoring the impact of geo-politics cannot engender a true understanding of oil security. Third, the model has the function of predicting the national energy strategy and energy transport design line in advance, which has more practical significance and instructional value to the maintenance of national energy security. Fourth, the model has the characteristics of mutagenicity, materializing specifically in the form of higher geo-oil security instability than in the original with the increase in behavior subjects in the process of scale conversion.

Through empirical analysis of the model, we further confirm the conclusion of earlier papers [19], namely, that the truly decisive role in Russia's Pacific oil pipeline dispute is played by the contention regarding oil geo-strategic security and strategic interests. National balance of power determines the scale political range of the oil pipeline, and the scale conversion of oil politics will alter the power between countries, further influencing geo-oil security. However, it must be clear that the geo-oil security discussed in this thesis only refers to national energy security problems regarding Russia's Pacific oil pipeline construction, which are caused by the changing geopolitical environment resulting from different pipeline routes. Therefore, the geopolitical energy security index that was designed and evaluated does not illustrate the national energy security situation, which involves all of a nation's energy imports and exports, energy supply and demand, energy use safety, and so on. Regarding the Pacific oil pipeline construction, contentions between China and Russia, China and Japan, and Russia 
and Japan have come to an end. However, it is not the end but a beginning for such issues. The target of Russian oil geo-strategy is not confined to China-Japan; it actually comprises the whole of Northeast Asia and even America. With the increase in behavior subjects, particularly the participation of South Korea and the United States, this situation will further increase the threat to China's oil energy security. Therefore, China must conduct sufficient analysis, prepare in advance, and guard against a rainy day.

With the rapid development of Chinese economy, China needs more energy to support. However, most of China's oil energy depends on import. Therefore, situations similar to that of the Russian pacific oil pipeline construction will continue to happen. Thus, In the future, the first thing is to clear all pipelines of China's energy import; second, we should evaluate the geo-energy security of each imported energy pipeline; finally, we should put forward the corresponding countermeasures and suggestions.

\section{Acknowledgments}

This work was supported by National Key Technology R\&D Program (2012BA12B03), the Natural Science Foundation of China (41171097).

\section{Author Contributions}

Zhiding Hu played an important role in the conception of the study, performing the data analyses, drafting and revising the manuscript. Yuejing Ge contributed to the conception of the study and played an important role in interpreting of the results and approved the final version.

\section{Conflicts of Interest}

The authors declare no conflict of interest.

\section{References}

1. Zhang, L. Discussion about the energy security of China. China Soft Sci. 2000, 11, 5-10.

2. Energy Strategy Research Team. Research on the Strategy of China's Energy Sustainable Development; Science Press: Beijing, China, 2006; p. 5.

3. Liu, L.T.; Shen, L.; Zhang, Y. Regional differences in energy security of China: A case study of Guangdong and Shaanxi Provinces. Resour. Sci. 2011, 33, 2386-2393.

4. Cai, G.T.; Zhang, L. Progress in China's energy security research. Prog. Geogr. 2005, 24, 79-87.

5. Hughes, L. The four "R"s of energy security. Energy Policy 2009, 37, 36-41.

6. Markandya, A.; Pemberton, M. Energy security, energy modeling and uncertainty. Energy Policy 2010, 38, 1609-1613.

7. Mamdouh, G.S. The new frontiers for the United States energy security in the 21 st century. Appl. Energy 2003, 76, 135-144.

8. Cabalu, H.L. Indicators of security of natural gas supply in Asia. Energy Policy 2010, 38, 218-225.

9. Kruyt, B.; van Vuuren, D.P.; de Vries, H.J.M.; Groenenberg, H. Indicators for energy security. Energy Policy 2009, 37, 2166-2181. 
10. Liu, Y. A possible solution to energy production and supply in the industrial zone of the Yangtze Valley. Geogr. Res. 1996, 15, 12-19.

11. Liu, Y. Measures for problems of energy issues and supply in China's coastal region. Acta Geogr. Sin. 1999, 54, 509-515.

12. Zhang, L.; Huang, Y.X.; Yang, B.; Li, J.-S.; Cheng, X.-L. Time-Space coordination of national energy supply. J. Nat. Resour. 2012, 27, 529-539.

13. Lang, Y.H.; Wang, L.M.; Wang, D.M. International experience of the rational energy use and $\mathrm{CO}_{2}$ emission reduction. Prog. Geogr. 2004, 23, 28-34.

14. He, X.J.; Wu, C.G.; Sheng, C.M.; Liu, Z.J. Research on the Evaluation and Countermeasures of China 's Energy Security; China Land Press: Beijing, China, 2010; pp. 2-14.

15. Sébille-Lopez, P. Oil Geopolitics; Social Sciences Academic Press: Beijing, China, 2008; p. 23.

16. Lang, Y.H.; Wang, L.M. Russian energy geopolitic strategy and the prospects of Sino-Russia energy cooperation. Resour. Sci. 2007, 29, 201-206.

17. Lang, Y.H.; Wang, L.M. Evolution of petroleum geopolitical patterns and China's policy response. Resour. Sci. 2008, 30, 1778-1783.

18. Lang, Y.H.; Wang, L.M. Geopolitical pattern of World's petroleum supply plates and the driving-force system of gravity center forward. China Energy 2009, 31, 7-13.

19. Xu, J.W.; Ge, Y.J. A geopolitical analysis of Russia's Pacific oil pipeline construction. Northeast Asia Forum 2011, 4, 51-62.

20. Ju, K.Y.; Zhou, D.Q.; Wang, Q.W.; Wu, J. Relationships between the energy consumption structure and energy security in China. Resour. Sci. 2010, 32, 1692-1697.

21. Hu, Z.D.; Ge, Y.J.; Xu, J.W.; Cao, Y. Space and the theoretical construction of economic geography. Prog. Geogr. 2012, 31, 676-685.

22. Liu, Y.G.; Wang, F.L. Concept of scale in human geography and politics of scale-Based on anglophone human geography since 1980s. Hum. Geogr. 2011, 26, 1-6.

23. Taylor, P.J. A materialist framework for political geography. Trans. Inst. Br. Geogr. 1982, 7, 15-34.

24. Smith, N. Uneven Development: Nature, Capital and the Production of Space; Blackwell: Cambridge, MA, USA, 1990; p. 12.

25. Cox, K.R. Spaces of Globalization: Reasserting the Power of the Local; Guilford: New York, NY, USA, 1998; pp. 156-178.

26. Herod, A.; Wright, M.W. Geographies of Power: Placing Scale; Blackwell: Oxford, NJ, USA, 2002; pp. 45-67.

27. Bernner, N. Global cities, glocal states: Global city formation and state territorial restructuring in contemporary Europe. Rev. Int. Polit. Econ. 1998, 5, 1-37.

28. Marston, S. The social construction of scale. Prog. Hum. Geogr. 2002, 24, 219-242.

29. Flint, C.; Taylor, P.J. Political Geography: World-Economy, Nation-State and Locality; Prentice Hall: New Jersey, NJ, USA, 2007; pp. 26-28.

30. Liu, Y.G.; Wang, F.L. Politics of scale in "Sanlu-Milkpowder Scandal". Acta Geogr. Sin. 2011, 66, 1368-1378.

31. Brenner, N. The limits to scale? Methodological reflections on scalar structuration. Prog. Hum. Geogr. 2007, 25, 591-614. 
32. Buzan, B. People, States and Fear: An Agenda for International Security Studies in the Post-Cold War Era; Lynne Rienner: Boulder, CO, USA, 1991; pp. 23-45.

33. Terriff, T. Security Studies Today; Polity Press: Cambridge, UK, 1999; p. 10.

34. Booth, K. Critical Security Studies and World Politics; Lynne Rienner: Boulder, CO, USA, 2005; pp. 27-62.

35. Zheng, X.W. "Security" in the context of globalization: The reconstruction of a concept. Int. Forum 2006, 8, 47-53.

36. Battistella, B. International Relations Theory; Social Sciences Academic Press: Beijing, China, 2010; p. 78.

37. Haftendorn, H. The security puzzles: Theory building and discipline in international security. Int. Stud. Q. 1991, 35, 3-17.

38. Wolfers, A. Discord and Collaboration; Johns Hopkins University Press: Baltimore, MD, USA, 1962; p. 150.

39. Buzan, B.; Wæver, O.; Wilde, J.D. A New Framework for Analysis; Lynne Rienner Publishers: London, UK, 2003; pp. 245-250.

40. Wu, C.G.; He, X.J. Sheng, C.; Liu, Z.; Wan, H. Comprehensive method for evaluating energy security. J. Nat. Resour. 2011, 26, 964-970.

41. Zhou, Q. Game on energy resources policies among nations based on the security of energy resources supply: Comment on Sino-Russia's argument on "Angarsk-Daqingline" and "Angarsk-Nakhodka line". China Ind. Econ. 2003, 12, 57-63.

42. Willrich, M. Energy World Politics; Free Press: New York, NY, USA, 1978; pp. 123-145.

43. Wang, E.Y. Political Geography: The Political Landscape in the Space-time; Higher Education Press: Beijing, China, 2003; p. 156.

44. Cao, Y.W. Russia's Pacific oil pipeline and the Northeast Asia's geopolitical layout. Sib. Stud. 2007, 34, 82-85.

45. Wang, J.J. The analysis of Russian oil exportation. Sib. Stud. 2006, 33, 17-20.

(C) 2014 by the authors; licensee MDPI, Basel, Switzerland. This article is an open access article distributed under the terms and conditions of the Creative Commons Attribution license (http://creativecommons.org/licenses/by/3.0/). 